\title{
TERRA E TERRITÓRIO NA PRODUÇÃO DIDÁTICA DOS TREMEMBÉ: UMAANÁLISE DE CONTEÚDO \\ E DISCURSO
}

\author{
LAND AND TERRITORY IN THE DIDACTIC PRODUCTION OF \\ TREMEMBÉ: AN ANALYSIS OF CONTENT AND SPEECH
}

\section{TIERRA Y TERRITORIO EN LA PRODUCCIÓN DIDÁCTICA DE LOS TREMEMBÉ: UN ANÁLISIS DE CONTENIDO Y DISCURSO}

\author{
Daniel Valério Martins ${ }^{1}$ \\ Universidade Federal da Grande Dourados - UFGD \\ Dourados, Mato Grosso do Sul, Brasil \\ jjfadelino@hotmail.com \\ ORCID: 0000-0003-0777-9750 \\ Ruan Rocha Mesquita ${ }^{2}$ \\ Universidade Federal do Ceará - UFC \\ Dourados, Mato Grosso do Sul, Brasil \\ rocharuan@live.com \\ ORCID: 0000-0002-0766-2133
}

\begin{abstract}
Resumo: No presente artigo apresentamos um recorte de uma pesquisa de Martins (2019) sobre um material didático produzido por estudantes indígenas da etnia Tremembé, que está localizada na região litorânea do nordeste brasileiro no distrito de Almofala, no município de Itarema-Ceará. Tal recorte foi realizado nos trabalhos de conclusão de curso do Programa de Magistério Indígena Tremembé Superior, Magistério Pé no Chão, desenvolvido em parceria com a Universidade Federal do Ceará que culminou na publicação de 19 livros e um DVD, de autoria indígena em Filho et al, (2014). Foi observada a educação diferenciada, como uma ferramenta utilizada na busca pelo desenvolvimento local, com a formação de professores qualificados, responsáveis por propagar o ativismo indígena na conscientização do alunado. Partimos da ideia central de analisar os estudos realizados na produção dos trabalhos de conclusão de curso Indígena Tremembé Superior, no tocante a temática Terras e Território. Em posse desse material, utilizamos uma metodologia voltada para o Paradigma Indiciário de Ginzburg (1989), e em seguida realizamos as análises de Conteúdo e Discurso de Bardin (2009) e Greimas (1975) apud Gregolin (1995, p.15) e Mazière (2017), observando a oralidade

1 Pós-Doutorado em História Indígena pelo Instituto Histórico e Geográfico de Santa Catarina, Doutor em Educação pela Universidade de Burgos/ES, Doutor em Antropologia pela Universidade de Salamanca/ES e professor no Programa de Pós Graduação em Educação e Territorialidade, Universidade Federal da Grande Dourados - UFGD.

2

Graduando em Sistemas e Mídias Digitais pela Universidade Federal do Ceará.
\end{abstract}


indígena e o processo de transcrição e registro dela em sua produção de textos didáticos, em um processo de sobrevivência e manutenção da cultura indígena.

Palavras-chave: Terra. Território. Educação. Desenvolvimento. Saberes tradicionais.

Abstract: In this article we present an excerpt from a research by Martins (2019) on educational material produced by indigenous students of the Tremembé ethnic group, which is in the coastal region of northeastern Brazil in the Almofala district, in the municipality of Itarema - Ceará. This cut was made in the course conclusion works of the Tremembé Superior Indigenous Teaching Program, Magisterium Pé no Chão, developed in partnership with the Federal University of Ceará that culminated in the publication of 19 books and a DVD, of indigenous authorship in Filho et al, (2014). Differentiated education was observed, as a tool used in the search for local development, with the training of qualified teachers, responsible for spreading indigenous activism in the awareness of students. We start from the central idea of analyzing the studies carried out in the production of the conclusion works Indigenous Tremembe Superior course, regarding the thematic Land and Territory. In possession of this material, we used a methodology focused on the Indigenous Paradigm of Ginzburg (1989), and then performed the Content and Discourse analysis of Bardin (2009) and Greimas (1975) apud Gregolin (1995, p.15) and Mazière (2017), observing indigenous orality and the process of transcribing and retrieving the production of didactic texts, in a process of survival and maintenance of indigenous culture.

Keywords: Land. Territory. Education. Development. Traditional knowledge.

Resumen: En el presente artículo, presentamos un extracto de una investigación de Martins (2019) sobre un material educativo elaborado por estudiantes indígenas de la etnia Tremembé, que se ubica en la región costera del noreste de Brasil en el distrito de Almofala, en el municipio de Itarema - Ceará. Tal recorte fue sacado de las conclusiones de los trabajos de fin de grado del Programa Superior de Enseñanza Indígena Tremembé, Magisterio Pé no Chão, desarrollado en conjunto con la Universidad Federal de Ceará que culminó con la publicación de 19 libros y un DVD, de autoría indígena en Filho et al, (2014). Fue observada la educación diferenciada como herramienta utilizada en la búsqueda del desarrollo local, con la formación de docentes calificados, responsables de difundir el activismo indígena en la conciencia de los estudiantes. Partimos de la idea central de analizar los estudios realizados en la producción de trabajos de conclusión de curso Tremembé, con el tema en torno de los conceptos de Tierra y Territorio. En posesión de este material, utilizamos una metodología enfocada en el Paradigma Indiciario de Ginzburg (1989), y luego realizamos el análisis de Contenido y Discurso de Bardin (2009) y Greimas (1975) apud Gregolin (1995, p.15) y Mazière (2017), observando la oralidad indígena y el proceso de transcripción y recuperación de estos en su producción de textos didácticos, en un proceso de supervivencia y mantenimiento de la cultura indígena.

Palabras-clave: Tierra. Territorio. Educación. Desarrollo. Conocimiento Tradicional.

Data de recebimento: $13 / 10 / 2020$

Data de aprovação: $20 / 12 / 2020$ 


\section{1 - INTRODUÇÃO}

Os povos indígenas do Ceará, ao longo dos anos e da luta por suas identidades, terras, territórios e reconhecimento social, buscam, na Educação, o meio alternativo para conseguir manter e propagar sua cultura, que vem sendo sufocada pelo padrão de sociedade que lhe rodeia. O processo educacional diferenciado, nestas comunidades indígenas, se torna indispensável, "uma vez que se trata de pequenas comunidades, com poucos habitantes e não suficientemente desenvolvidas para manter a todos com seus recursos naturais e escassas oportunidades de emprego". (MARTINS,2016).

Desse modo, em uma das pesquisas de Martins (2019), analisando os trabalhos de conclusão de curso de formação de professores dos alunos Tremembé, o autor percebeu que a produção indígena estava diretamente associada às chamadas de atenção sobre problemas enfrentados pela comunidade, chegando a enumerá-las da seguinte forma: 1 - Terras e territórios; 2 - Meios de Subsistência e Pesca; 3 - Educação e educação diferenciada; 4 - História e resgate histórico e 5 - Medicina, cultura, mitos e lendas. Portanto, delimitou como objeto de sua pesquisa a produção científica de 19 livros e um DVD, publicados pela Universidade Federal do Ceará tendo como autores os alunos indígenas Tremembé do projeto de Licenciatura Intercultural Indígena, MITS - Magistério Indígena Tremembé Superior.

Assim, diante do que foi exposto, por meio de uma metodologia voltada ao Paradigma Indiciário de Ginzburg (1989), e Análise de Conteúdo e Discurso de Bardin (2009) e Greimas (1975) apud Gregolin (1995, p.15) e Mazière (2017), neste artigo buscou-se verificar e analisar os resultados da produção direcionada ao bloco relacionado à questão de Terras e territórios (primeiro ponto das chamadas de atenção), bem como seus impactos e contribuições na teorização da educação indígena antes somente obtidas por informações orais.

A abordagem proposta a desenvolver neste artigo está vinculada em evidenciar a intencionalidade política e pedagógica da educação indígena a serviço do coletivo indígena em sua produção textual e seu poder de abertura na contemporaneidade, e dessa maneira, observar o vínculo e comprometimento com as lutas pela democracia e emancipação, seja cultural, política, social ou territorial, à medida que apresenta crítica à questão dialética entre modernidade e colonialidade e entre oralidade e escrita.

Ressalta-se, antes de tudo, que o Ceará possui 14 comunidades indígenas reconhecidas e outras em processo de reconhecimento, de modo que se aspira colaborar com o desenvolvimento sociocultural pela difusão e produção científica, através da educação intercultural diferenciada, visto que tais comunidades foram influenciadas pelo processo de demarcação territorial tendo como resultado não somente um processo de aculturação ${ }^{3}$ ocasionado pelo contato e sim de adculturação ${ }^{4}$, ou seja, não somente perda, mas também soma de culturas. (SCHADEN, 1969 apud MARTINS 2020).

3 Podemos observar em Schaden (1969), o processo de aculturação, não somente como resultado de imposição cultural, mas como elemento e temática de estudo que deve ser visto como necessidade de transformação em um processo somatório e gerador de transculturas, sendo necessária uma ferramenta como a educação intercultural.

4 Aguirre Beltrán (1992), faz uma distinção entre aculturação e adculturação onde assegura que a primeira significa contacto e perda de culturas enquanto adculturação significa a soma de culturas. 


\section{2 - CAMINHOS METODOLÓGICOS: INDÍCIOS, CONTEÚDO E DISCURSO}

Segundo Ginzburg (1989), o Paradigma Indiciário, metodologia norteadora deste artigo, está baseado na investigação de pistas, sinais ou indícios reveladores acerca dos fenômenos da realidade, que muitas vezes são imperceptíveis para a maioria, mas que permite ao pesquisador interpretar as singularidades e originalidades do objeto estudado. Nesse sentido, utilizamos como referência a obra "Mitos, Emblemas, Sinais: Morfologia e História", especificamente no texto "Sinais: Raízes de um Paradigma Indiciário" de Carlo Ginzburg (1989), por ser um modelo traçado na elaboração do conhecimento a partir da investigação minuciosa e análise refinada dos indícios, dados e sinais. Os indígenas já possuem a capacidade nata de observação de sinais, indícios das forças da natureza por meio da vivência e experimentação e assim nos dão o suporte para a afirmação da matriz indígena do Paradigma Indiciário.

Para a análise de conteúdo nos apoiamos em Bardin (2009). Segundo a autora, a Análise de Conteúdo (AC) se configura como uma gama de "tentativas que se fazem no campo alargado da análise de comunicações: lexicometria, enunciação linguística, análise de conversação, documentação e base de dados, etc.", em síntese, a "análise de conteúdo se faz pela prática" (Bardin, 2009, p.27), estando nesse caso vinculada ao conceito de Ginzburg (1989).

Para a Análise de Discurso (AD), trabalhamos de acordo com Greimas (1975) citado por Gregolin (1995, p.15) e Mazière (2017). Quando abordam a análise de discurso em três níveis: fundamental, narrativo e discursivo. Fundamental, refere-se à ideia central ou "de que trata o texto". Nível narrativo é dividido em quatro fases: manipulação, competência, performance e sanção, que explicam que manipulados por uma situação o indivíduo é levado a querer agir frente ao problema, então precisa adquirir competência para realizar a ação e após adquiri-la realiza a performance, ou seja, pratica a ação que trará uma consequência ou sanção positiva ou negativa. O nível discursivo é onde se contextualiza, indivíduo, tempo e espaço geográfico.

Portanto, o fazer ciência Tremembé, desperta um olhar para detalhes minuciosos e símbolos, possibilitando avaliar que o Paradigma Indiciário se mostra como metodologia apropriada para esse campo temático, uma vez que nos obriga a um olhar sensível e atento à configuração das práticas educativas em um contexto local, que se complementará quando associado as análises de Conteúdo e Discurso, onde os indígenas serão ouvidos, suas práticas tradicionais transcritas e seus pensamentos sobre suas terras e territórios inferidos com maior precisão.

\section{3 - PRÉ-ANÁLISE E DIVISÃO EM BLOCOS DE CHAMADAS DE ATENÇÃO EM MARTINS (2019)}

De acordo com Martins (2019), depois de uma pré-análise do material escolhido como objeto de seu estudo, ou seja, das 20 monografias dos estudantes indígenas Tremembé, com base no paradigma indiciário, chegou-se à conclusão da existência de cinco blocos, que em primeiro momento foram relacionados com alguns indícios sendo, nesse caso os problemas enfrentados pelas comunidades indígenas e ao mesmo tempo que poderia tratar-se de chamadas de atenção para essas adversidades. 
Os blocos foram ordenados de acordo com as temáticas abordadas e separados da seguinte forma: 1) terras e territórios; 2) meios de subsistência e pesca; 3) educação e educação diferenciada; 4) história e resgate histórico e 5) medicina, cultura, mitos e lendas. Prosseguindo, foi aplicado no bloco 1) terras e territórios a metodologia de AC, seguida da $\mathrm{AD}$ com base nos indícios observados na tentativa de detectar as chamadas de atenção, de interesses e os símbolos nas temáticas abordadas pelos alunos indígenas. Abaixo segue a imagem das capas de todas as monografias dos alunos Tremembé.

Figura 1 - Capas das monografias produzidas pelos alunos indígenas do Programa de Magistério Indígena Tremembé Superior, Magistério Pé no Chão, Itarema - Ceará.

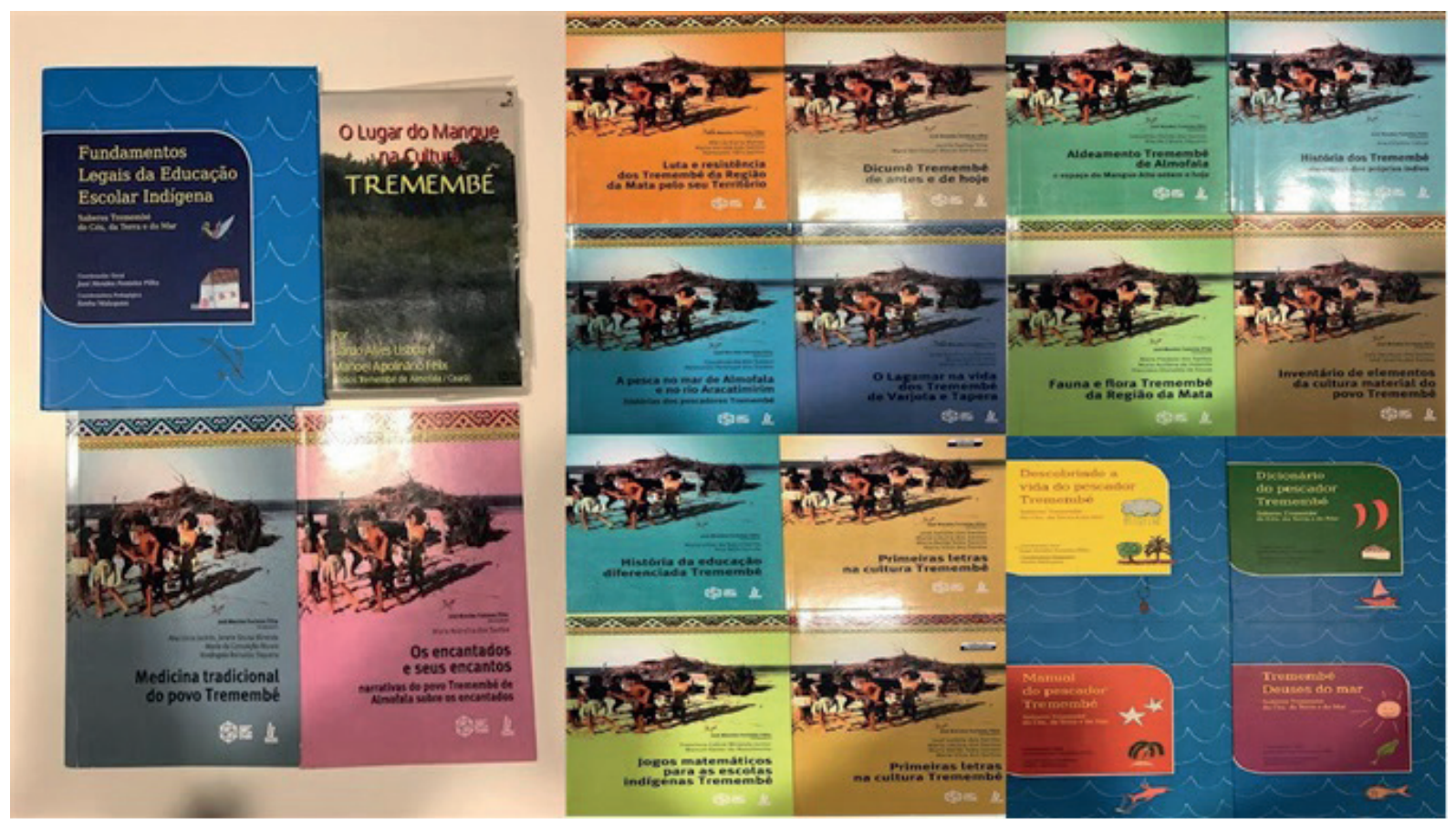

Fonte: Martins, 2019, p. 181-183

Em sua pesquisa, Martins (2019), dividiu cada bloco, elencado de acordo com a quantidade de livros (títulos) sobre cada temática como apresentado no quadro abaixo: 
Figura 2 - Livros e blocos resultantes de pesquisas produzidas pelos alunos indígenas do Programa de Magistério Indígena Tremembé Superior, Magistério Pé no Chão, Itarema - Ceará.

\begin{tabular}{|c|c|}
\hline Quantidade de livros & Temas Abordados \\
\hline 4 livros 1 DVD & Terras e territórios \\
\hline 5 livros & Meios de subsistência/pesca \\
\hline 4 livros & Educação/ educação diferenciada \\
\hline 3 livros & História/ resgate histórico \\
\hline 3 livros & Medicina /cultura/mitos e lendas \\
\hline
\end{tabular}

Fonte: Martins, 2019, p.76

A reflexão inicial a partir da abordagem $\mathrm{AC}$ revela que se trata de um conjunto de técnicas de análise das comunicações, por meio de procedimentos sistemáticos e objetivos dos conteúdos, das mensagens e indicadores, permitindo a inferência de conhecimentos sobre as condições de produção ou recepção dessas mensagens.

Esse método ocorre em três fases: pré-análise (organização); exploração do material (codificação, decomposição ou enumeração); tratamento dos resultados e inferência. Para a análise de Discurso (AD), trabalhamos, entre outros, de acordo com Greimas (1975) citado por Gregolin (1995, p.15), quando nos diz que: “(...) um texto é formado por uma estrutura que articula diferentes elementos e constitui um sentido coeso e coerente". O autor salienta que um texto, na visão da $\mathrm{AD}$ pode se constituir de três níveis: 1. Um nível fundamental: ponto de partida de geração de sentido no texto (relação de diferença entre dois termos dentro de um universo semântico); 2. Um nível narrativo: narra o percurso gerativo de sentidos e de valores fundamentais a partir de um sujeito, por meio de quatro fases: manipulação, competência, performance e sanção; 3. Um nível discursivo: converte as estruturas narrativas em discursos quando assumidas pelo sujeito da enunciação, contextualizando sujeito, tempo e lugar.

Também se adota o pensamento de Mazière (2017), quando nos diz que a AD "configura enunciados a analisar em corpora construídos, geralmente heterogêneos, segundo um saber assumido, linguístico, histórico, político e filosófico". Assim observa-se que o discurso está estruturado, levando em consideração todos esses aspectos agrupados e não de maneira isolada.

\section{4 - TERRAS E TERRITÓRIOS NA INFERÊNCIA DAS ANÁLISES}

Nesse ponto foi realizado o recorte das 20 obras de produção indígena e como explicado anteriormente, delimitou-se o artigo referente ao bloco Terras e Territórios na inferência de Martins (2019). Assim afunila-se o objeto de análise na produção indígena de 4 livros, sendo: 1) O Lugar do Mangue na Cultura Tremembé; 2)Luta e Resistência dos Tremembé 
da Região da Mata pelo seu Território; 3)Aldeamento Tremembé de Almofala: o Espaço do Mangue Alto Ontem e Hoje; 4)Fauna e Flora Tremembé da Região da Mata e um DVD: O Lagamar na Vida dos Tremembé de Varjota e Tapera, que abordam a temática sobre Terras e Territórios, seja na esfera histórica, como no âmbito de demarcações de fronteiras até mesmo sobre a exploração dos recursos naturais por parte de posseiros, fazendeiros e empresários.

Com relação a conceituação de Fronteiras, utiliza-se o pensamento de Amante (2014), quando retrata as Fronteiras como espaços de construção e protestos identitários, enquadrando bem em seus aspectos mencionados à questão territorial indígena e a luta por demarcação. E assim confrontar as novas fronteiras com um pensamento intercultural referente ao contato e a interação cultural, ajustando-se a ideia de Candau (2008) em que as sociedades formadas por diferentes grupos socioculturais necessitam buscar a interculturalidade, uma vez que; "A perspectiva intercultural está orientada à construção de uma sociedade democrática, plural, humana, que articule políticas de igualdade com políticas de identidade”(p.52).

\subsection{ANÁLISE DE CONTEÚDO COM BASE NOS PRESSUPOSTOS DE BARDIN (2009)}

Observa-se em Martins (2019) que esse recorte apresenta uma breve análise de estudos etnográficos realizados por um grupo de professores indígenas das escolas diferenciadas e não elaborado de forma individual, no decorrer do curso de Magistério Indígena Tremembé (MIT) e o Magistério Indígena Tremembé Superior (MITS). Trata-se de livros que fazem parte da coleção "Magistério Pé no Chão", publicado em Fortaleza, no ano de 2014.

Martins (2019) conclui que todo o material passa a ser apresentado como material paradidático ou didático descrevendo os objetivos dos materiais a serem utilizados por professores com a finalidade de contribuir com o conhecimento e reconhecimento da história da comunidade indígena Tremembé para em seguida versar sobre a territorialidade Tremembé.

Utiliza-se como exemplo um dos capítulos do livro "Luta e Resistência dos Tremembé da Região da Mata pelo seu Território". O segundo capítulo denominado "O povo Tremembé e seu Território", situa o povo Tremembé no que se refere aos aspectos geográficos, históricos, culturais sociais, econômicos e religiosos.

O material também aborda sobre a invasão de empresas que passaram a explorar os recursos naturais da região, como exemplos citam a invasão da Ducoco (empresa de exploração do coco) e as resistências na Região da Mata, relatando como se deu a invasão da empresa Ducoco no território Tremembé nas localidades de Tapera e Varjota no Ceará e a luta dos indígenas pelo direito de permanecer em suas terras.

Os autores (alunos Tremembé), relatam a luta e resistência Tremembé, a criação do salão base, sede da primeira escola e espaço de reuniões para planejamentos das ações de resistência aos problemas gerados pela empresa Ducoco, que se instalou na região, trazendo medo e tortura física e psicológica para a população Tremembé, bem como outros problemas como os impactos causados pela invasão citando exemplos como: migração, exploração, seca e outros. Mas, como inferência, foi observado como elemento de discussão central, a demarcação das terras indígenas, além de demonstrar as relações de poder que se estabelecem 
contra o povo Tremembé e as denúncias sobre a invasão de suas terras e exploração delas com empresas locais, instaladas em território indígena.

\subsection{ANÁLISE DE DISCURSO}

Ao analisar o material do bloco Terras e Territórios na obra de Martins (2019), sob a ótica da $\mathrm{AD}$ percebe-se outra visão epistemológica frente ao científico que traz como base a linguagem e os sentidos explícitos nos discursos dos personagens dos textos. Seguindo essa mesma linha de raciocínio, observam-se algumas partes que mostram os níveis da Análise de Discurso no material.

Percebe-se na fala da história de luta e resistência do povo Tremembé da região da mata contra a invasão da empresa Ducoco a ênfase nos termos "luta", "resistência" e "invasão", além dos conceitos de Terra e de Território, como ponto de partida que darão sentido a toda narrativa. Por serem os dois primeiros ("luta" e "resistência") considerados valores positivos, contrapondo-se ao terceiro ("invasão"), nesse viés, visto como negativo, observamos os pontos de terra e território, que desde a perspectiva de demarcação, se chegaria a uma sanção positiva.

Tais sentidos perpassam as relações apresentadas durante toda narrativa do texto em análise sendo considerado, portanto como nível 1 da (AD). O nível dois, referente a narrativa no sentido de valores, é perceptível no percurso descritivo do texto, quando mostra a manipulação da empresa Ducoco sobre a população Tremembé, com o propósito de invadir suas terras, ao mesmo tempo em que causa a destruição em diversos aspectos, em um eterno jogo de sedução, com promessas de trabalho, moradia, escola e até hospital.

Esses aspectos podem ser notados nas falas de alguns moradores da comunidade explícitas nos textos, citadas por Filho et al (2014, p.20 e 21).

A) "De imediato, as ações ameaçadoras e repressivas da Ducoco recaíram sobre a Tapera. Toda área foi cercada e os moradores obrigados a receber indenizações pelas benfeitorias ali existentes". (...) "Em face da destruição de suas antigas moradias, as famílias que não tinham para onde ir obtiveram permissão da empresa para construir novas casas numa pequena extensão de terras alagadiças, próximo do mangue, nas margens do rio". (...) (OLIVEIRA JUNIOR, 1998, p.65). B) "Eles chegaram prometendo casa para os moradores, terra para trabalhar; quem tivesse um jumentinho, podia vender que eles iam dar trator para ajudar nos trabalhos; que daria escolas para os filhos e até hospital" (Tio Trival, liderança da Tapera).

De acordo com Martins (2019) os textos relatam que mesmo diante da pressão sofrida por meio da ação de empresas instaladas na comunidade, houve resistência indígena, mostrando competência ao buscar alternativas coletivas que pudessem contribuir na luta contra a citada empresa. Assim, observamos o que na AD chama-se de "saber", "poder" e "querer". Os textos revelam o apoio da igreja católica, bem como a busca por conhecimentos jurídicos, pois somente os saberes e práticas tradicionais não seriam suficientes para a luta indígena. 
Mencionam também algumas tentativas pouco exitosas, destacando a demarcação de uma pequena parcela de terra pelo Usucapião, em que construíram o Salão da Varjota, registrado nos textos como marco histórico de importância na resistência do povo Tremembé, lugar de reuniões, primeira escola e símbolo da comunidade.

Nesse sentido, nota-se também em Martins (2019) que a performance do texto aparece nas ações diversas contra a invasão das terras da comunidade por empresas e fazendeiros, dentre essas ações podemos citar: reação dos moradores que se reuniram para conversar e pensar, decidindo procurar a igreja para buscar conhecimento; dialogar com a empresa para tentar uma negociação amigável; contactar as aldeias para buscar respaldo na lei; conquistar terras pelo Usucapião e construção do Salão da Varjota.

Já como última fase o que na AD, Gregolin (1995) chama de sanção, verifica-se que toda luta e resistência dos Tremembé representa alguns indícios de sanção positiva por suas conquistas, tais como o direito a terra e território para continuar buscando junto à justiça e a demarcação deles. Porém, os aspectos que podem se caracterizar como sanção negativa ainda lideram, pois até os dias atuais, o processo de demarcação da terra Tremembé encontra-se paralisado, esperando a conclusão de perícia antropológica.

Identifica-se também que os autores (alunos Tremembé), relatam que a influência das empresas instaladas em território Tremembé retarda o processo de demarcação e homologação das terras indígenas, conforme observado no material em análise, quando os autores apresentam o relato do Pajé Luiz Caboclo:

“A relação da comunidade com a empresa está sendo feita através da justiça,
e assim nós vamos nos relacionando com ela mais dessa forma. Os índios
que estão trabalhando lá, por um lado, é muito ruim, porque dá a entender
que nós estamos a favor da empresa, mas do outro lado a gente vê que é
devido a precisão das famílias, devido a destruição que a Ducoco trouxe que
foi muito grande, a falta de opção e por não ter para onde ir. Não é porque ela
é boa até porque o nosso povo trabalha como escravo para ela. (...)” (FILHO
et al, 2014, p.48).

Seguindo a AD, percebe-se o nível 3 na estrutura do texto, chamado de nível discursivo, que segundo Gregolin $(1995$, p.16) se caracteriza como o patamar mais superficial do percurso gerativo de sentido. Segundo o autor: "As estruturas narrativas convertem-se em discurso quando assumidas pelo sujeito da enunciação: ele faz uma série de "escolhas", de pessoa, de espaço, de tempo e de figuras", contando a história a partir de um determinado "ponto de vista".

Nos textos em análise, o sujeito da enunciação conta com as seguintes opções:

a) Os personagens são identificados explicitamente no texto, por meio de características que os tornam visíveis, muitos deles até nomeados pelos autores;

b) A espacialização está bem caracterizada, frisada e demarcada desde o início ao fim como "povo Tremembé da área da mata" e mais especificamente "das aldeias de Varjota e Tapera", localizadas no "Aldeamento de Almofala (Itarema-CE)"; 
c) A temporalização em que se deu todo contexto de produção do texto apresenta-se de maneira indefinida, quando os autores dizem que este foi resultado de anos de estudo de um grupo de professores, que fizeram o Magistério Indígena Tremembé e o Magistério Indígena Tremembé Superior, no entanto o texto teve sua conclusão no ano de 2014. Porém, se forem levados em consideração os recortes temporais mencionados durante a narrativa que dá sentido a todos os textos em interlocução com o contexto dos personagens, têm-se períodos que contam, desde o início da colonização, passando pelo século XVI e século XVIII, até o período mais importante da discussão, entre os anos 1975 e 1979 quando ocorre a ação crucial da invasão da empresa Ducoco, no território Tremembé.

\section{5 - RESULTADOS E DISCUSSÕES}

Através das análises aplicadas, foi evidenciado que os indígenas Tremembé estão utilizando a Educação Diferenciada como ferramenta e arma na luta por mudanças sociais, uma vez que utilizam de forma crítica e reivindicatória, ou seja, foram capazes de perceber a importância, repercussão e visibilidade que alcançariam com esse material, que atravessou fronteiras e serviu inclusive de estudos na Europa na universidade de Burgos, como objeto de estudo de desenvolvimento de uma tese no Programa de Doutorado em Educação.

Em outras palavras, o que buscam e deixaram registrado nesse material é uma visibilidade da luta pela demarcação e posse de suas terras ocupadas, pois sem terras e territórios não existe comunidade indígena e meios de subsistência, que com o passar dos anos foram sendo roubados por posseiros e empresas que ali se instalaram.

Também buscam que essa reivindicação se fortaleça e se propague com a Educação Diferenciada e que essa possa contar suas verdadeiras histórias e não expor o indígena como povos que viveram, comeram, andavam e sim, conjugar esses verbos no presente, pois nunca deixaram de existir, com seus costumes, tradições, lendas, mitos e até mesmo sua medicina e suas curas realizadas pelos pajés, que utilizam entre seus ritos o Torém.

Segundo Martins (2019), o Torém mencionado nas obras analisadas, com base no Paradigma Indiciário de Ginzburg, pode ser compreendido como um dos principais símbolos Tremembé, diretamente associado ao território e identidade. Se refere a um ritual de dança circular, expressão corporal bem marcada, utilizado em momento de evidenciar a ancestralidade, em épocas especiais e em situações de chamadas de atenção, mostrando a luta da comunidade, e se tornando o principal elemento marcador da singularidade Tremembé e ao mesmo tempo principal ferramenta de luta pela visibilidade e na reconquista de suas terras e territórios.

O esquema estrutural abaixo mostra o Torém como o ápice da construção do ser indígena, onde o mesmo com base na terra e no território, consolida sua identidade e gera uma transformação no olhar do outro sobre a comunidade indígena, pois ao participar do Torém como ritual ou dança, o visitante por meio dessa interação, sairá transformado, entendendo o Torém como elemento cultural, mas também como elemento político de diferenciação e demarcação. 
Figura 3 - O Torém
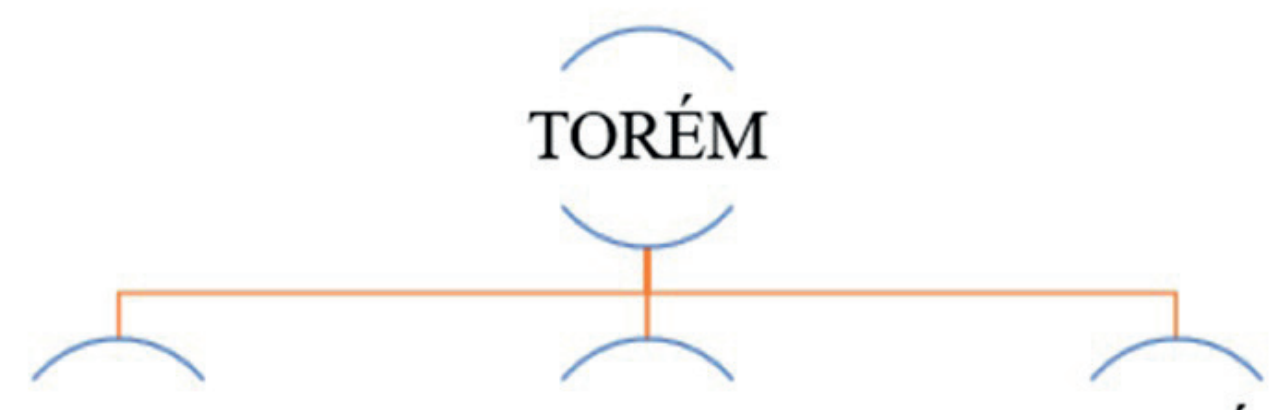

TERRA

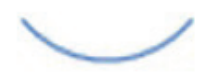

IDENTIDADE

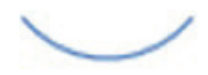

\section{TERRITÓRIO}

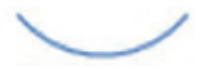

Fonte: Martins, 2019, p.80

Os indígenas Tremembé destacam o sentimento de amor pela terra quando expressam que "a terra não tem um dono". Eles visualizam a terra como uma mãe, como um elemento sagrado da natureza. Em seus discursos, os indígenas expressam, também, ferrenhas críticas aos inimigos da natureza, à exemplo dos exploradores dos recursos naturais e os posseiros que agem em atendimento aos interesses do capital

\section{6 - CONSIDERAÇÕES FINAIS}

Diante desta situação, depara-se não somente com as principais necessidades, mas também de elementos fundamentais para a constituição de uma comunidade indígena, pois de acordo com os próprios indígenas, se não existe terra e território demarcado não existe uma justificativa da existência de uma comunidade.

O tema Terras e Território está também diretamente relacionado com a categoria identidade, estando em total acordo com Hall (1978), quando parte de uma ideia de alteridade, onde um "eu" necessita do contato com um "outro", para observar nas diferenças o fortalecimento identitário, nesse caso, observado na fronteira entre "identidade e diferença", reitera-se assim a justificativa e importância em fincar o pé na luta por uma educação diferenciada, uma educação voltada para as especificidades Tremembé, justificando também a produção de um material de retroalimentação desse modelo educacional, que servirá de base para as lutas travadas pela demarcação de suas terras e território, como em um sistema cíclico.

Por fim, constata-se que toda a luta por demarcação e homologação territorial, que resultou na morte de alguns membros da comunidade Tremembé e a perda da história de base oral com a morte dos sábios anciãos, está evidenciada na escrita, assim como a necessidade por sua subsistência, mencionando aqui seus bosques, invadidos de certo modo, por empresas locais, bem como a concorrência desleal na atividade pesqueira entre os moradores e 
empresas instaladas nos seus territórios.

Quanto a abordagem sobre uma Educação Diferenciada, vemos a necessidade da perpetuação da sua cultura e dos saberes tradicionais Tremembé, ou seja, a valorização e importância de manter uma educação que fortaleça a cultura indígena, que tenha um currículo desenhado por membros da própria comunidade e que sirva de arma na luta indígena.

Pondera-se portanto, que no material de produção Tremembé, além da necessidade de registrar a história contada desde o ponto de vista dos próprios indígenas, em uma perspectiva Emic $^{5}$, se observa o material como uma bandeira da luta indígena e uma chamada de atenção para toda essa luta e resistência indígena, onde se inicia pela demarcação da terra, contra a invasão por posseiros e empresas, a favor de uma educação diferenciada ou até mesmo por seus elementos culturais como forma de comprovação de propriedade.

O resultado disso é uma transformação na historiografia, onde o indígena deixa de ser objeto e passa a ser sujeito ativo da narrativa e escritor de sua própria história e cultura.

5 Segundo o linguista Pike (1954) os termos Emic e Etic, fazem referência aos conceitos de fonêmico e fonético. As ciências sociais se apropriaram dos termos para os trabalhos etnográficos, onde o termo Emic, "desde dentro", faz referência ao pensamento interno de uma determinada cultura e o que falam seus membros sobre seus padrões culturais. 


\section{7 - REFERÊNCIAS}

AGUIRRE BELTRÁN, G. El proceso de aculturación y el cambio sociocultural de México. México: F.C.E, 1992.

AMANTE, M. Das fronteiras como espaço de construção e contestação identitária às questões da segurança. São Paulo: Etnográfica, 2014.

BARDIN, L. Análise de Conteúdo. Lisboa: Edições 70 LDA, 2009.

CANDAU, V. Direitos Humanos, educação e interculturalidade: as tensões entre igualdade e diferença. Rio de Janeiro: Revista Brasileira de Educação, vol.13, no.37, p. 45-56, jan./abr. 2008.

FILHO, J. M. F. (org.); ALVES, E.L.; FÉLIX, M.A. O lugar do Mangue na Cultura Tremembé. Fortaleza: Universidade Federal do Ceará-UFC, 2014.

FILHO, J. M. F. (org.); DOS SANTOS, M. I.; MATIAS, M. M.; FÉLIX, R. J. Luta e Resistência dos Tremembé da Região da Mata pelo seu Território. Fortaleza: Imprensa Universitária, 2014.

FILHO, J. M. F. (org.); DOS SANTOS, S. O.; SIQUEIRA, R. C. Aldeamento Tremembé de Almofala: o Espaço do Mangue Alto Ontem e Hoje. Fortaleza: Imprensa Universitária, 2014.

FILHO, J. M. F. (org.); DOS SANTOS, M. P.; DE HOLANDA, M. A.; DE SOUSA, F. E. Fauna e Flora Tremembé da Região da Mata. Fortaleza: Imprensa Universitária, 2014.

FILHO, J. M. F. (org.); GUILHERME, J. R.; FÉLIX, M. J.; JACINTO,M. L. O Lagamar na Vida dos Tremembé de Varjota e Tapera. Fortaleza: Imprensa Universitária, 2014.

GILL, R. Análise de Discurso. Petrópolis: Vozes, 2002.

GINZBURG, C. Mitos, Emblemas e Sinais. São Paulo: Cia das Letras, 1990.

GREGOLIN, M. D. A Análise do Discurso: conceitos e aplicações. São Paulo: Ed. Alfa, 1995. GREIMAS, A. Sobre o sentido: Ensaios Semióticos. Rio de Janeiro: vozes, 1975.

HALL, S. Más Allá de la Cultura. Barcelona: Gustavo i Gili, 1978.

MARTINS, D. V. A Intraculturalidade nas Comunidades Indígenas da Região Metropolitana de Fortaleza-CE, Brasil: Caminho para o Desenvolvimento e Sobreculturalidade. Salamanca: Ediciones Vitor, 2016.

MARTINS, D. V. A Contribuição Científica dos Tremembé a través da Educação Diferenciada e Intercultural com base nos Saberes Tradicionais. Burgos: Universidad de Burgos, 2019. 
MARTINS, D. V. A Aculturação Indígena de Egon Schaden como base conceitual e justificativa do processo de Sobreculturalidade. Revista do Instituto Histórico e Geográfico de Santa Catarina. Florianópolis, v03, p. 148-174, out. 2020.

MAZIÈRE, F. A Análise do Discurso: História e Prática. São Paulo: Parábola, 2017.

OLIVEIRA JUNIOR, G. A. Torém, Brincadeiras dos Índios Velhos. São Paulo: Annablume, 1998.

PIKE, K. L. Emic and Etic Standpoints for the Description of Behaviour. Glendale: Summer Institute of Linguistics, 1954.

SCHADEN, E. Aculturação Indígena. São Paulo: Editora da USP. 1969. 